\title{
Disappearance of Oral Lichen Planus After Liver Transplantation for Primary Biliary Cirrhosis and Immunosuppressive Therapy in a 63-year-Old Japanese Woman
}

\author{
Yumiko Nagao ${ }^{1, *}$; Michio Sata ${ }^{1,2}$ \\ ${ }^{1}$ Department of Digestive Disease Information and Research, Kurume University School of Medicine, Kurume, Japan \\ ${ }^{2}$ Division of Gastroenterology, Department of Medicine, Kurume University School of Medicine, Kurume, Japan \\ *Corresponding Author: Yumiko Nagao, Department of Digestive Disease Information and Research, Kurume University School of Medicine, 67 Asahi-machi, $830-0011$ Kurume, Japan. \\ Tel: +81-942317902, Fax: +81-942317820; E-mail: nagao@med.kurume-u.ac.jp
}

Received: November 21, 2013; Revised: December 29, 2013; Accepted: January 6, 2014

\begin{abstract}
Introduction: There are few reports concerning association between primary biliary cirrhosis (PBC) and lichen planus. In addition, there is only one report about lichen planus after liver transplantation.

Case Presentation: We describe a case of oral lichen planus (OLP) accompanied with PBC that resolved following liver transplantation 14 years later. This patient received immunosuppressive drugs after liver transplantation.

Discussion: The disappearance of OLP might be due to immunosuppressive therapy following liver transplantation. Further observations and studies are necessary to clarify the relationship between OLP and PBC.
\end{abstract}

Keywords: Lichen Planus, Oral; Liver Cirrhosis, Biliary; Liver Transplantation

\section{Introduction}

The association between oral lichen planus (OLP) and hepatitis $\mathrm{C}$ virus (HCV) infection has been reported frequently $(1,2)$. In Japan, the rate of HCV infection in OLP is especially high (3). On the other hand, the association between lichen planus and primary biliary cirrhosis (PBC) been reported rarely since Seehafer et al. pointed it out in 1981 (4). PBC is a chronic cholestatic liver disease of adults. Progressive bile-duct injury from portal and periportal inflammation leads to progressive fibrosis and eventually, cirrhosis (5). Evidences to date suggest that the disease might be caused by immunological and genetic factors. Affected individuals are typically middle-aged women with asymptomatic rises of serum biochemical markers of hepatic injury.

An epidemiological study from United States showed that one-third of 1032 patients with $\mathrm{PBC}$ were affected by another autoimmune disease, most commonly Sjögren's syndrome, Raynaud's phenomenon, autoimmune thyroid disease, scleroderma, or systemic lupus erythematosus (SLE) (6). Oleaga et al. previously reported a case of generalized lichen planus associated with $\mathrm{PBC}$, which cleared after liver transplantation (7). We report a case of OLP accompanied by PBC that disappeared after liver transplantation.

\section{Case Presentation}

In January 1995, a 45 year old Japanese female presented at the Kurume University Hospital (Fukuoka, Japan) with a burning pain in the bilateral buccal mucosa on eating and drinking. The lesion was diagnosed as OLP by biopsy (Figure $1 \mathrm{~A}$ ). The biopsy specimen was characterized by hyperparakeratosis with thickening of the granular layer, a subepithelial band of infiltration of lymphocytes and liquefied degeneration of the basal cell layer. The histopathological findings were consistent with a diagnosis of OLP. The erosive OLP lesion was not widely aggravated by application of steroids. She consulted an oral surgeon at our hospital every six months to detect chenges in the oral lesion.

Concerning her history, she had been hospitalized for aggravation of liver function tests at the ages of 20 (in 1970) and 23 (in 1973). In August, 1992, the 42-year-old patient was admitted to a nearby hospital, again because of aggravation of liver function and icterus. Data from that time were obtained from her family doctor included aspartate aminotransferase (AST) $547 \mathrm{U} / \mathrm{L}$ (normal range, 1333), alanine aminotransferase (ALT) $818 \mathrm{U} / \mathrm{L}$ (normal range, 6-30), total bilirubin (T. Bil) $10.5 \mathrm{mg} / \mathrm{dL}$ (normal range, 0.30-1.20), albumin (Alb) $3.3 \mathrm{~g} / \mathrm{dL}$ (normal range, 4.005.00), negative results for anti-HCV antibody (anti-HCV), 
serum HCV RNA, hepatitis B surface antigen (HBsAg), IgM antibody to hepatitis B core antigen (IgM anti-HBc), hepatitis B surface antibody (anti-HBs), IgM antibodies to hepatitis A virus (IgM anti-HAV), antimitochondrial antibodies (AMA), anti-smooth muscle antibody (SMA), liver kidney microsome antibody type 1 (LKM-1), and positive results for anti-nuclear antibody (ANA). After hospitalization, she was treated with oral ursodeoxycholic acid (UDCA) by her family doctor for liver cirrhosis caused by autoimmune hepatitis (Table 1). The patient did not receive systemic steroid therapy.

Hypertension was noted at the age of 42 years and treatment with an antihypertensive drug was started. In addition, she was diagnosed with Sjögren's syndrome at the age of 42 years. There was no history of blood transfusion or tattooing and her family history was not contributory. The laboratory data at her first visit for examination of oral membrane disease in 1995 were AST 31 U/L, ALT 23 $\mathrm{U} / \mathrm{L}$, gamma-glutamyl transpeptidase (gamma-GTP) 34 $\mathrm{U} / \mathrm{L}$, total protein (T. pro) $7.4 \mathrm{~g} / \mathrm{dL}$, Alb $4.1 \mathrm{~g} / \mathrm{dL}$, T. Bil $1.5 \mathrm{mg} /$ $\mathrm{dL}$, direct bilirubin (D. Bil) $0.8 \mathrm{mg} / \mathrm{dL}$, negative results for anti-HCV, serum HCV RNA, and HBsAg (Table 1).

Because the patient had a progressive worsening of her symptoms including fatigue and pruritus around June 2008 (at 58-years-old), she was admitted to our hospital for a detailed evaluation of her liver disease in June 2009. The investigations findings included elevation of ALP and IgM but negative results for AMA, complication of osteoporosis with biliary stasis, compression fractures of the third and fourth lumbar vertebrae from osteoporosis, complication of Sjögren's syndrome and chronic thyroiditis, pruritus, and erosive OLP. Based on these findings, she was diagnosed as progressive PBC for the first time. The likelihood of the patient's 6-month survival was $22 \%$, in accordance with The Updated Natural History Model for $\operatorname{PBC}(8,9)$. The updated Mayo model includes five independent variables predicting survival: age, serum levels of bilirubin and albumin, prothrombin time, and the presence or absence of peripheral edema, including response to diuretic therapy.

This patient was treated as an inpatient by branched chain amino acids (BCAA), UDCA, diuretic drug, and antithyroid agent. The symptom of OLP did not aggravate. She had some teeth extracted for chronic apical periodontitis and received liver transplantation from a living donor in September 2009. Treatment with immunosuppressive agents such as tacrolimus (Prograf $®$ ) and mycophenolate mofetil (CellCept $®$ ) was started. In May 2011, the symptoms of OLP disappeared (Figure 1 B). In addition, the clinical condition of PBC improved (Table 1).

Table 1. Summary of the Clinical Condition of Oral Lesion and Laboratory Data

\begin{tabular}{|c|c|c|c|c|c|c|c|}
\hline & $\begin{array}{l}\text { Normal } \\
\text { Range }\end{array}$ & $\begin{array}{l}\text { On Admission } \\
\text { to a Previous } \\
\text { Hospital }\end{array}$ & $\begin{array}{l}\text { First Visit } \\
\text { to Examine } \\
\text { Oral Lesions }\end{array}$ & $\begin{array}{l}\text { On Admis- } \\
\text { sion to This } \\
\text { Hospital }\end{array}$ & $\begin{array}{l}\text { Liver Trans- } \\
\text { plantation }\end{array}$ & $\begin{array}{l}\text { After Liver } \\
\text { Transplanta- } \\
\text { tion }\end{array}$ & Recent Visit \\
\hline Date & & Aug 21, 1992 & Jan 17, 1995 & Jun 23, 2009 & Sep 1, 2009 & May 17, 2011 & Aug 27, 2013 \\
\hline Age, y & & 42 years old & 45 years old & 59 years old & 59 years old & 61 years old & 63 years old \\
\hline $\begin{array}{l}\text { Clinical } \\
\text { Condition of } \\
\text { Oral Lesion }\end{array}$ & & unknown & $\begin{array}{l}\text { OLP }^{\mathrm{a}} \text { pres- } \\
\text { ence, biopsy }\end{array}$ & OLP presence & & $\begin{array}{l}\text { OLP disap- } \\
\text { pearance }\end{array}$ & $\begin{array}{l}\text { OLP disap- } \\
\text { pearance }\end{array}$ \\
\hline \multicolumn{8}{|l|}{$\begin{array}{l}\text { Laboratory } \\
\text { Data }\end{array}$} \\
\hline $\mathbf{A S T}^{\mathrm{a}}, \mathbf{U} / \mathbf{L}$ & $13-33$ & 547 & 31 & 53 & & 21 & 25 \\
\hline $\mathbf{A L T}^{\mathrm{a}}, \mathbf{U} / \mathbf{L}$ & $6-30$ & 818 & 23 & 25 & & 13 & 19 \\
\hline T. pro ${ }^{\mathrm{a}}, \mathrm{g} / \mathbf{d L}$ & $6.70-8.30$ & 10.5 & 7.4 & 5.84 & & 7.45 & 7.08 \\
\hline $\mathbf{A l b}^{\mathrm{a}}, \mathrm{g} / \mathbf{d L}$ & $4.00-5.00$ & 3.3 & 4.1 & 2.34 & & 4.86 & 4.41 \\
\hline $\begin{array}{l}\text { gamma GTP } \\
\mathrm{a}, \mathrm{U} / \mathbf{I}\end{array}$ & $10-47$ & unknown & 34 & 33 & & 22 & 16 \\
\hline $\operatorname{ALP}^{a}$ & $115-359$ & unknown & ND & 513 & & 238 & 141 \\
\hline $\begin{array}{l}\text { T. BIl }{ }^{\mathrm{a}}, \mathrm{mg} / \\
\mathrm{dL}\end{array}$ & $0.30-1.20$ & 10.50 & 1.50 & 10.70 & & 1.33 & 0.94 \\
\hline $\begin{array}{l}\text { D.Bil }{ }^{\mathrm{a}} \text {, mg/ } \\
\text { dL }\end{array}$ & $\leq 0.60$ & unknown & 0.80 & 6.71 & & 0.18 & 0.13 \\
\hline T. $C^{\mathrm{a}}, \mathrm{mg} / \mathrm{dL}$ & $128-219$ & 95 & $\mathrm{ND}^{\mathrm{a}}$ & 97 & & 227 & 209 \\
\hline $\mathbf{H b}{ }^{\mathrm{a}}, \mathbf{g} / \mathbf{d L}$ & $11.0-15.0$ & unknown & ND & 11.9 & & 14.5 & 13.7 \\
\hline $\begin{array}{l}\text { PLT }^{a}, \times 10 \\
4 / \mu L\end{array}$ & $13.0-36.0$ & unknown & ND & 7.0 & & 11.4 & 15.5 \\
\hline $\mathbf{A F P}^{\mathrm{a}}, \mathbf{n g} / \mathbf{m L}$ & $\leq 8.7$ & unknown & ND & 3.2 & & 4.5 & 4.0 \\
\hline
\end{tabular}


Nagao Yet al.

\begin{tabular}{|c|c|c|c|c|c|c|}
\hline $\operatorname{IgA}^{\mathrm{a}}, \mathrm{g} / \mathbf{d L}$ & $103-409$ & unknown & ND & 274 & ND & ND \\
\hline $\operatorname{IgM}^{\mathrm{a}}, \mathrm{mg} / \mathrm{d}$ & $40-221$ & unknown & ND & 236 & ND & 110 \\
\hline $\operatorname{IgG}^{\mathrm{a}}, \mathrm{mg} / \mathrm{dL}$ & $918-1742$ & unknown & ND & 1309 & ND & ND \\
\hline FT4 ${ }^{\mathrm{a}}, \mathbf{n g} / \mathrm{dL}$ & $0.88-1.56$ & unknown & ND & 1.27 & ND & ND \\
\hline TSH $^{\mathrm{a}}, \mu \mathrm{IU} / \mathbf{L}$ & $0.210-3.850$ & unknown & ND & 5.040 & ND & ND \\
\hline Anti-HCV ${ }^{a}$ & & negative & negative & negative & ND & ND \\
\hline $\begin{array}{l}\text { Serum HCV } \\
\text { RNA }\end{array}$ & & negative & negative & negative & ND & ND \\
\hline HBsAg ${ }^{a}$ & & negative & negative & negative & ND & ND \\
\hline $\begin{array}{l}\text { IgM anti- } \\
\operatorname{HBc}^{\mathrm{a}}\end{array}$ & & negative & ND & ND & ND & ND \\
\hline Anti-HBs ${ }^{a}$ & & negative & ND & ND & ND & ND \\
\hline Anti-HBc ${ }^{a}$ & & ND & ND & negative & ND & ND \\
\hline $\begin{array}{l}\text { IgM anti- } \\
\text { HAV }^{\mathrm{a}}\end{array}$ & & negative & ND & ND & ND & ND \\
\hline $\mathbf{A M A}^{\mathrm{a}}$ & & negative & ND & ND & ND & ND \\
\hline SMA $^{\mathrm{a}}$ & & negative & ND & negative & ND & ND \\
\hline LKM-1 ${ }^{\text {a }}$ & & negative & ND & negative & ND & ND \\
\hline ANA $^{a}$ & & positive & ND & positive & ND & ND \\
\hline
\end{tabular}

a Abriviations:AFP, alpha-fetoprotein;Alb, albumin; ALP, alkaline phosphatase; ALT, alanine aminotransferase; AMA, antimitochondrial antibodies; ANA, antinuclear antibody; Anti-HBs, hepatitis B surface antibody; Anti-HBc, hepatitis B core antibody; Anti-HCV, anti-HCV antibody; AST, aspartate aminotransferase; D.Bil, direct bilirubin; FT4, free thyroxine 4; gamma GTP, gamma-glutamyl transpeptidase; Hb, hemoglobin; HBsAg, hepatitis B surface antigen; IgM anti-HBc, IgM antibody to hepatitis B core antigen; IgM anti-HAV, IgM antibodies to hepatitis A virus; LKM-1, liver kidney microsome antibody type 1; ND, not detected; PLT, platelets; T.pro, total protein; T.BIl, total bilirubin; T.C, total cholesterol; TSH, thyroid stimulating hormone; SMA, anti-smooth muscle antibody

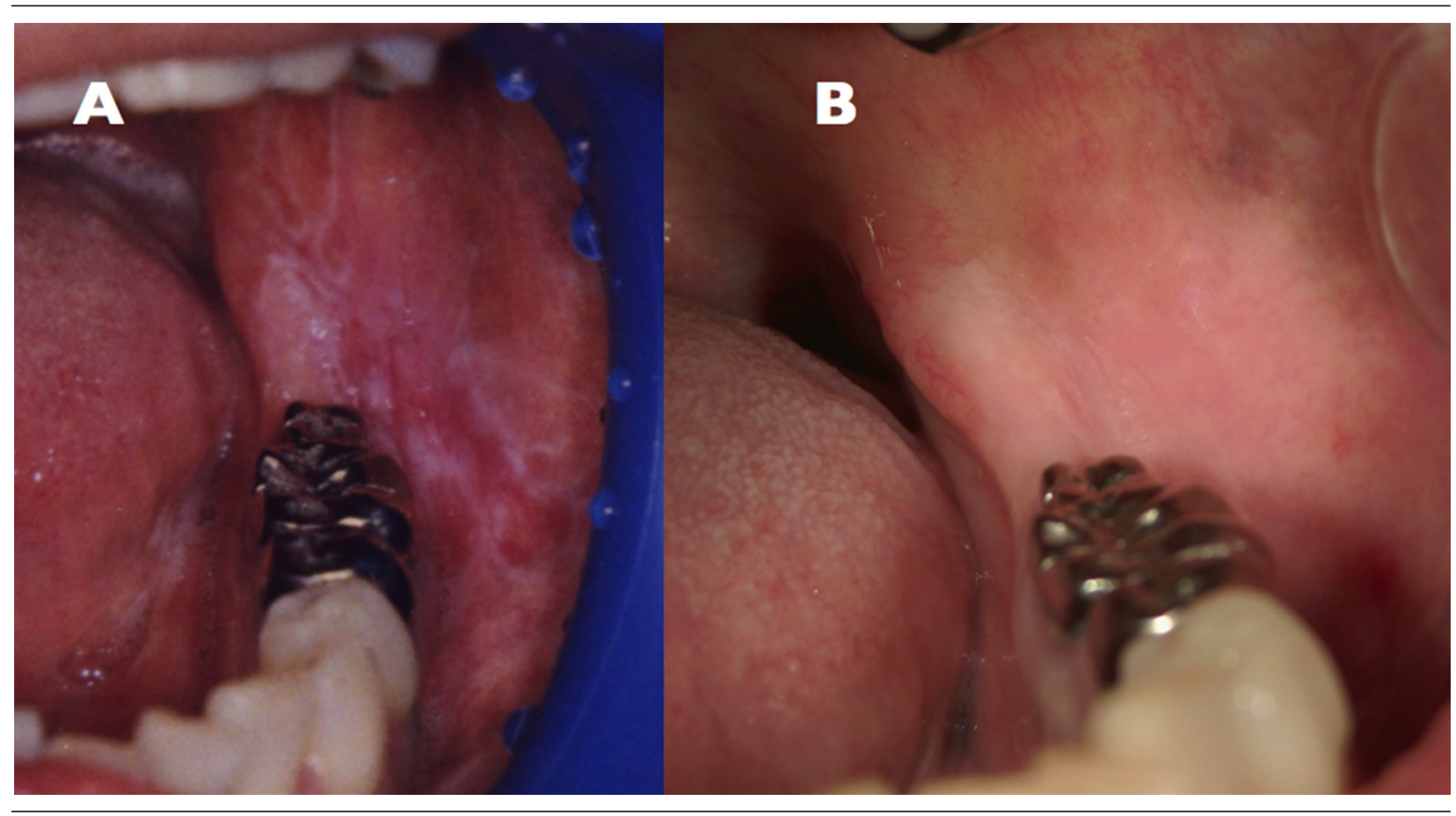

Figure 1. (A) OLP Lesions Affecting the Bilateral Buccal Mucosa (January 1995),(B) Disappearance of OLP(May 2011) 


\section{Discussion}

PBC patients present with a wide variety of cutaneous manifestations, varying in severity (10). Koulentaki et al. reported that the incidence rates of cutaneous lichen planus and OLP in patients with PBC were 10.2\% (5/49 cases) and $8.2 \%(4 / 49)$, respectively (10). Powell et al. reported that the incidence rates of lichen planus in $\mathrm{PBC}$ without D-penicillamine (d-PCN) therapy and after d-PCN therapy were $2.6 \%$ (7/268 cases) and $12.9 \%$ (17/131), respectively (11). In Japan, there are no lepidemiologic studies concerning association between $\mathrm{PBC}$ and lichen planus.

Liver transplantation can be successful in treating endstage liver disease from PBC (12). The survival of liver transplant recipients with $\mathrm{PBC}$ diminishes significantly at risk scores above 7.8 (13). Following transplantation, the majority of patients receive immunosuppressive therapy consisting of combinations of corticosteroids, azathioprine, cyclosporine, and tacrolimus.

In previous studies, the effect of immunosuppressive agents such as tacrolimus and mycophenolate mofetil on severity and progression of OLP were repoted (14-16). Tacrolimus inhibits the activation and proliferation of T-lymphocytes by inhibiting the phosphatase activity of calcineurin and mycophenolate mofetil inhibits lymphocyte proliferation and activation. However, Lodi et al. reported that these agents theoretically could also trigger malignant transformation (17). It has been reported that the topical use of tacrolimus in patients with OLP may promote the development of squamous cell carcinoma (18). For example, cyclosporin can promote cancer progression, both by a direct cellular effect and by an effect on the host's immune system (19).

In a retrospective study, Wimmer et al. analyzed the development of de novo malignancy after successful liver transplantation of 609 patients (20). The most frequent observed tumors were non-melanoma skin cancers (44.83\%). Moreover, post-transplant lymphoid disease, oropharyngeal cancer $(n=6,6.9 \%)$, upper gastrointestinal tract cancer $(n=4$, $4.6 \%)$, lung cancer $(n=4,4.6 \%)$, gynecological malignancies ( $\mathrm{n}=4,4.6 \%)$, and kidney cancer $(\mathrm{n}=3,3.45 \%)$ were detected. Multivariate analysis revealed recipient age (hazards ratio (HR) 1.06), male gender (HR 1.73), and tacrolimus-based immunosuppression (HR2.06) as significant risk factors.

In conclusion, immunosuppressive therapy following liver transplantation for PBC led to the disappearance of OLP lesion in our patient as was previously reported by Oleaga et al. (7). Patients with PBC are at increased risk of occurrence of hepatocellular carcinoma and extrahepatic malignancies (21). Long-term follow-up is needed to elucidate the therapeutic effects of transplantation.

\section{Acknowledgements}

The authors have nothing to declare.

\section{Authors' contributions}

Yumiko Nagao carried out most of the data collection and drafted the manuscript. Michio Sata contributed to data analysis. All authors have read and approved the final manuscript.

\section{Financial disclosure}

The authors have nothing to declare.

\section{Funding/support}

This study was supported in part by a Grant-in-Aid for Scientific Research (C) (No.22592354) from the Ministry of Education, Culture, Sports, Science and Technology of Japan.

\section{References}

1. Lodi G, Pellicano R, Carrozzo M. Hepatitis $C$ virus infection and lichen planus: a systematic review with meta-analysis. Oral Dis. 2010;16(7):601-12.

2. Shengyuan L, Songpo Y, Wen W, Wenjing T, Haitao Z, Binyou W. Hepatitis $C$ virus and lichen planus: a reciprocal association determined by a meta-analysis. Arch Dermatol. 2009;145(9):1040-7.

3. Nagao Y, Sata M, Tanikawa K, Itoh K, Kameyama T. Lichen planus and hepatitis $\mathrm{C}$ virus in the northern Kyushu region of Japan. Eur J Clin Invest. 1995;25(12):910-4.

4. Seehafer JR, Rogers RS, 3rd, Fleming CR, Dickson ER. Lichen planus-like lesions caused by penicillamine in primary biliary cirrhosis. Arch Dermatol.1981;117(3):140-2.

5. Talwalkar JA, Lindor KD. Primary biliary cirrhosis. The Lancet. 2003;362(9377):53-61.

6. Gershwin ME, Selmi C, Worman HJ, Gold EB, Watnik M, Utts J, et al. Risk factors and comorbidities in primary biliary cirrhosis: a controlled interview-based study of 1032 patients. Hepatology. 2005;42(5):1194-202.

7. Oleaga JM, Gardeazabal J, Sanz de Galdeano C, Diaz PJ. Generalized lichen planus associated with primary biliar cirrhosis which resolved after liver transplantation. Acta Derm Venereol. 1995;75(1):87.

8. Grambsch PM, Dickson ER, Wiesner RH, Langworthy A. Application of the Mayo Primary Biliary Cirrhosis Survival Model to Mayo Liver Transplant Patients. Mayo Clinic proceedings. Mayo Clinic. 1989;64(6):699-704.

9. Murtaugh PA, Dickson ER, Van Dam GM, Malinchoc M, Grambsch PM, Langworthy AL, et al. Primary biliary cirrhosis: prediction of short-term survival based on repeated patient visits. Hepatology. 1994;20(1 Pt 1):126-34.

10. Koulentaki M, Ioannidou D, Stefanidou M, Maraki S, Drigiannakis I, Dimoulios P, et al. Dermatological manifestations in primary biliary cirrhosis patients: a case control study. Am J Gastroenterol. 2006;101(3):541-6.

11. Powell FC, Rogers RS, Dickson ER. Primary biliary cirrhosis and lichen planus. J Am Acad Dermatol.1983;9(4):540-5.

12. Liermann Garcia RF, Evangelista Garcia C, McMaster P, Neuberger J. Transplantation for primary biliary cirrhosis: retrospective analysis of 400 patients in a single center. Hepatology. 2001;33(1):22-7.

13. Kim WR, Wiesner RH, Therneau TM, Poterucha JJ, Porayko MK, Evans RW, et al. Optimal timing of liver transplantation for primary biliary cirrhosis. Hepatology. 1998;28(1):33-8.

14. Morrison L, Kratochvil FJ, 3rd, Gorman A. An open trial of topical tacrolimus for erosive oral lichen planus. J Am Acad Dermatol. 2002;47(4):617-20.

15. Rozycki TW, Rogers RS, 3rd, Pittelkow MR, McEvoy MT, el-Azhary RA, Bruce AJ, et al. Topical tacrolimus in the treatment of symptomatic oral lichen planus: a series of 13 patients. J Am Acad Dermatol. 2002;46(1):27-34.

16. Wee JS, Shirlaw PJ, Challacombe SJ, Setterfield JF. Efficacy of mycophenolate mofetil in severe mucocutaneous lichen planus: a ret- 


\section{Nagao Yet al.}

rospective review of 10 patients. Br J Dermatol. 2012;167(1):36-43.

17. Lodi G, Scully C, Carrozzo M, Griffiths M, Sugerman PB, Thongprasom K. Current controversies in oral lichen planus: report of an international consensus meeting. Part 2. Clinical management and malignant transformation. Oral Surg Oral Med Oral Pathol Oral Radiol Endod. 2005;100(2):164-78.

18. Mattsson U, Magnusson B, Jontell M. Squamous cell carcinoma in a patient with oral lichen planus treated with topical application of tacrolimus. Oral Surg Oral Med Oral Pathol Oral Radiol Endod. 2010;110(1):e19-25.
19. Hojo M, Morimoto T, Maluccio M, Asano T, Morimoto K, Lagman $\mathrm{M}$, et al. Cyclosporine induces cancer progression by a cell-autonomous mechanism. Nature.1999;397(6719):530-4.

20. Wimmer CD, Angele MK, Schwarz B, Pratschke S, Rentsch M, Khandoga A, et al. Impact of cyclosporine versus tacrolimus on the incidence of de novo malignancy following liver transplantation: a single center experience with 609 patients. Transpl Int. 2013;26(10):999-1006.

21. Nijhawan PK, Therneau TM, Dickson ER, Boynton J, Lindor KD. Incidence of cancer in primary biliary cirrhosis: the Mayo experience. Hepatology.1999;29(5):1396-8. 